\title{
SOUSÂNDRAdE E MARTÍ: A AmÉrica CONTra A AMERICA
}

Júlio Pimentel Pinto

juliop@uol.com.br

Um nasceu em 1832; o outro, em 1853. O primeiro era brasileiro, maranhense, natural de Guimarães; o segundo, cubano e havanês. Morreram com sete anos de diferença: 1902 e 1895, respectivamente. Aquele que viveu menos, o segundo, é um dos pensadores americanistas hoje mais citados e celebrados. $\mathrm{O}$ mais longevo anda quase esquecido, apesar dos esforços de alguns poucos.

Façam-se as apresentações às claras: Joaquim de Souza Andrade - ou Sousândrade - e José Martí. Numa época em que os esforços expansionistas norte-americanos no sentido do Sul ganhavam clareza e ênfase, ambos viveram parte de sua vida em Nova York e escreveram contra os Estados Unidos, a America; ambos buscaram construir representações de outra América e a nomearam pelo emprego de prefixo ou de pronome possessivo: “Transamérica”, “Nossa América”. Era mais do que uma coincidência.

\section{II}

José Martí foi personagem importante nas lutas pela emancipação política de Cuba. Jovem, participou da primeira guerra de independência 
(1868-1878) e, ainda em seu decorrer, seguiu para o exílio. Circulou por Espanha, França, México, Guatemala, Venezuela, retornou ocasionalmente a Cuba e, afinal, se fixou em Nova York em 1881, quando os colonizadores espanhóis já haviam sufocado a rebelião cubana e reforçado o controle sobre aquela que, à época, era sua principal colônia nas Américas.

Jornalista, poeta, crítico de arte, ensaísta, Martí só voltou definitivamente a Cuba catorze anos depois, para morrer logo no início da segunda guerra de independência - que ainda prosseguiu até 1898 e terminou com sucesso parcial: a emancipação colonial foi obtida, mas o sonho de um país livre e soberano, longamente acalentado pelos chamados "autonomistas", desfez-se ante a experiência concreta da presença de tropas norte-americanas na ilha e dos diversos recursos legais que estabeleciam vínculos de fato entre Estados Unidos e Cuba. ${ }^{1}$

Nas lutas internas de Cuba, Martí sempre se alinhou com os "autonomistas". Ele combinava, na poesia e nos textos que escrevia para jornais, a defesa da independência de Cuba com a denúncia repetida dos esforços norte-americanos de expandir seus domínios sobre a ilha e sobre a América toda: Cuba como início e metáfora de uma ampla e progressiva hegemonia continental estadunidense. Em carta de 2 de novembro de 1889 , enviada ao jornal argentino La Nación e publicada em duas partes, nos dias 19 e 20 do mesmo mês, Martí relembrou o fato de os governos norte-americanos, historicamente, privilegiarem apenas seus interesses e confrontarem os vizinhos. Destacou a guerra contra o México e algumas ações armadas sobre a América Central e o Caribe. O objetivo central martiano, naquele momento, era questionar o discurso que os representantes dos Estados Unidos apresentavam na Primeira

${ }^{1}$ O embate entre "autonomistas" e "anexionistas" acompanhou todo o processo da independência cubana, ao longo do século XIX, e contaminou tanto as ações políticas e armadas, quanto o discurso emancipacionista. Para os "anexionistas”, a longa relação comercial entre a ilha e os Estados Unidos - iniciada e desenvolvida às costas ou sob os olhos complacentes da metrópole espanhola - justificava a anexação de Cuba ao vizinho do Norte, após a obtenção da independência. Mais: os "anexionistas" acreditavam que Cuba não se consolidaria política e economicamente como Estado independente, necessitando desse vínculo formal. Os "autonomistas", por seu lado, defendiam a total autonomia do novo Estado. A participação norte-americana na segunda guerra de independência de Cuba e a permanência da presença militar e da influência dos Estados Unidos transformaram a aparente vitória dos "autonomistas" (Cuba separou-se da Espanha e nasceu, em 1898, como Estado nacional supostamente livre) numa derrota efetiva; a lógica "anexionista" rapidamente se instaurou, traduzida, por exemplo, na instalação de base militar norte-americana em Guantánamo - tema hoje bastante debatido - e na conhecida Emenda Platt, de 1901. 


\begin{abstract}
Pimentel -17
Conferência Pan-Americana - então em curso em Washington -, em que enfatizavam a urgência das alianças continentais e defendiam, entre outras, a proposta de uma área de livre-comércio nas Américas:

Por que nos juntamos como aliados, no melhor da juventude, na batalha que os Estados Unidos se preparam para travar contra o resto do mundo? Por que se deveriam travar nas repúblicas da América as batalhas dos Estados Unidos com a Europa, ensaiando em povos livres seu sistema de colonização? Por que estão tão desejosos de entrar em casa alheia, enquanto os que querem pôr para fora dela estão entrando na sua própria casa? Por que acertar com todos os povos americanos projetos de reciprocidade na sala do congresso, quando um projeto de reciprocidade, o do México, acertado entre os dois governos, com vantagens mútuas, aguarda em vão, há muitos anos, a sanção do congresso, porque se opõem a ele, em detrimento geral da Nação, interesses especiais feridos no tratado? (MARTÍ, 1983, p. 180).
\end{abstract}

Martí apropriava-se de uma célebre metáfora de Abraham Lincoln a da casa dividida/ una $^{2}$ - para caracterizar o esforço unificador norte-americano como um ensaio de "colonização" do restante da América. A "unidade da casa americana", para o cubano, reforçava a posição dos Estados Unidos no cenário do comércio internacional, contra (especialmente) os interesses britânicos. A ideia de aliança obrigatória dos demais países americanos com os Estados Unidos também era rechaçada, por Martí, em nome de uma América que estava "no melhor da juventude", ou seja, vivia seus primeiros anos de formação autônoma, precisava preservar o vigor dos novos projetos nacionais e não se colocar à mercê de alianças que beneficiassem prioritariamente os Estados Unidos. A acusação, pelo texto, de não-reciprocidade é central: qualquer unidade só poderia existir - sugeria Martí - se o posicionamento de todos os membros fosse isonômico. No lugar da "fraternidade" americana alardeada pelos Estados Unidos, Martí via a tentativa de estabelecer um protetorado estadunidense, e encerrava a carta com palavras fortes:

O congresso internacional será o inventário da honra, quando se verá quem é que defende com energia e parcimônia a independência da América espanhola, onde está o equilíbrio do mundo; ou se existem nações capazes, pelo medo ou

${ }^{2} \mathrm{O}$ chamado "discurso da casa dividida" foi feito por Abraham Lincoln em junho de 1858, perante a convenção do Partido Republicano, que acabara de escolhê-lo candidato às eleições presidenciais norte-americanas. Na ocasião, ele se referia às tensões entre os estados predominantemente abolicionistas do Norte e os estados escravistas do Sul dos Estados Unidos. Três anos depois desse discurso, o país imergiu na violenta Guerra Civil, que durou quatro anos e atraiu bastante a atenção do então jovem Martí. 
pelo deslumbramento, pelo hábito de servidão ou pelo interesse de consentir, no continente ocupado por dois povos de natureza e objetivos diferentes, em diminuir, com sua deserção, as forças indispensáveis, e já poucas, com que a família de uma nacionalidade poderá conter, com o respeito que imponha e com a cordura que demonstre, a tentativa de predomínio, confirmada pelos fatos contemporâneos, de um povo criado na esperança da dominação continental, no momento em que aparecem, num apogeu comum, a ânsia de mercado de suas indústrias abarrotadas, a ocasião de impor a nações longínquas e a vizinhos fracos o protetorado prometido nas profecias, a forma material necessária para sua realização, e a ambição de um político ladrão e atrevido (MARTÍ, 1983, p. 185). ${ }^{3}$

A dura reação de Martí aos movimentos norte-americanos em direção ao Sul não era inusual. Tampouco era novidade a exigência moral de "honra" e de "virilidade" - valor varonil, viril - como condições obrigatórias para confrontar o avanço nortista. Em março daquele ano, ele já escrevera o famoso "Vindicação de Cuba", que confrontava artigo francamente ofensivo aos cubanos, publicado no jornal The Manufacturer, da Filadélfia. O texto do jornal americano apresentava os cubanos como "preguiçosos", "sem iniciativa”, "com aversão a todo esforço" e carentes de "força varonil” (MARTÍ, 1983, p. 149). A discussão girava, claro, em torno da dificuldade de Cuba para a obtenção de sua independência e da perspectiva "anexionista"; no artigo, Martí empenhava-se em mostrar que não havia qualquer grau de inferioridade dos cubanos frente aos norte-americanos. A resposta, porém, não se resumia à questão cubana e afirmava que a atitude estadunidense perante o resto da América enfatizava apenas o "valor da terra", sem considerar os povos que nela habitavam, sua história ou perspectivas futuras. Novamente, despontava o tema da "juventude americana” e a linha divisória entre aqueles que defendiam os interesses da América Hispânica - Cuba sempre como o princípio de um projeto maior de dominação americana - e os que preferiam a aliança com os Estados Unidos:

E é a verdade triste que nossos esforços ter-se-iam renovado com êxito, com toda probabilidade, se não fosse, em alguns de nós, pela esperança pouco viril dos anexionistas, de obter liberdade sem por ela pagar seu preço, e pelo temor justo dos outros, de que nossos mortos, nossas memórias sagradas, nossas ruínas encharcadas de sangue chegassem a ser apenas o adubo do solo para o crescimento de uma planta estrangeira, ou o motivo de uma piada para The Manufacturer da Filadélfia (MARTÍ, 1983, p. 151-152).

3 O "político ladrão e atrevido" das palavras de Martí era o Secretário de Estado norte-americano James G. Blaine, que propusera a realização da Conferência. 
Também o diagnóstico, presente na carta, de elementos da sociedade norte-americana que teriam contaminado os "anexionistas" e poderiam se prolongar pelo conjunto do território da América Hispânica era brutal: "individualismo excessivo", "adoração da riqueza", "júbilo prolongado de uma vitória terrível”, "apetite imoderado de poder", "triunfo contrário à bondade e à justiça”. A ânsia imoderada do lucro e a sagração da moeda eram os umbrais do expansionismo brutal. O sonho do mundo como uma imensa Wall Street - a mesma Wall Street, veremos adiante, alegorizada por Sousândrade como um "inferno" - estava na origem da corrosão dos valores morais e da liberdade, atestava Martí.

Quase dois anos depois da furiosa redação de "Vindicação de Cuba", o cubano levou às últimas consequências a recusa dos Estados Unidos como parceiro privilegiado e modelo para toda a América. Num artigo de janeiro de 1891, ele propôs a ideia de "Nossa América".

Após uma introdução em que defendia o valor superior das ideias frente às conquistas materiais - rejeição apriorística do consumo e das mercadorias associadas à dinâmica financeira e social norte-americana -, Martí celebrou o orgulho de ser americano e a importância da autonomia:

E em que pátria pode o homem ter mais orgulho do que em nossas repúblicas dolorosas da América, levantadas entre as massas mudas de índios, ao rumor da luta do livro contra o círio, sobre os braços ensanguentados de uma centena de apóstolos? De fatores tão desordenados, jamais, em menos tempo histórico, criaram-se nações tão adiantadas e compactas. (...) O governo deve nascer do país. O espírito do governo deve ser o do país. A forma de governo deverá concordar com a constituição própria do país. O governo não é mais que o equilíbrio dos elementos naturais do país (MARTÍ, 1983, p. 195-196).

A retórica marcada por repetições e ênfases associava o reconhecimento interno e as opções políticas à especificidade do processo histórico e à formação cultural de cada região, permitindo, dessa maneira, a autoidentificação e refutando a busca de semelhança com um vizinho distinto e sempre apresentado de forma a destacar sua agressividade ou disposição de envolver o outro. Na contramão das ações concatenadas pelo "tigre" ou "polvo" Estados Unidos, e recorrendo a espantosas metáforas alimentares e à regular louvação do empenho - sempre viril - dos jovens, Martí definia a singularidade da América Hispânica:

Os jovens da América arregaçam as mangas, põem as mãos na massa e a fazem crescer com a levedura de seu suor. Entendem que se imita demais e que a salvação é criar. Criar é a palavra-chave desta geração. O vinho é de banana; e se sair ácido, é o nosso vinho! (MARTÍ, 1983, p. 199). 
Duas páginas depois, o texto encerrava-se num tom otimista e convicto, de conclamação e anúncio do inarredável futuro americano:

Porque já ressoa o hino unânime; a atual geração leva às costas, pelo caminho adubado por seus pais sublimes, a América trabalhadora; do rio Bravo ao estreito de Magalhães, sentado no dorso do condor, espalhou o Grande Semi, nas nações românticas do continente e nas ilhas doloridas do mar, a semente da América nova! (MARTÍ, 1983, p. 201).

Mais do que singular e agregadora, a América Hispânica era uma feliz novidade, fundada no registro mítico do Grande Semi, espírito ancestral positivo e propiciatório, e transplantada para o futuro que Martí via - e, sobretudo, desejava - para o continente.

Evidentemente, restava o problema da nomeação. "América”, um termo originalmente genérico, fora apropriado, já no final do século XVIII, por uma parte do continente, os Estados Unidos, que assumiram discursivamente a vocação de Novo Mundo que o termo implicava e nele encontraram a possibilidade de articular, sob uma noção suficientemente abrangente e adequadamente imprecisa, as treze colônias que se tornaram independentes em 1776. A outra parte da América - aquela que, na segunda metade do século XX, nos habituamos a chamar de "Latina" - tornara-se, assim, uma América dependente de alguma especificação; na lógica daqueles que refutavam sua adesão pura e direta aos Estados Unidos, essa América que não era America precisava ser nomeada. A sugestão de Martí foi simultaneamente simples, pragmática e ambiciosa: "Nossa América". O pronome possessivo já aparecia no título do texto, que, assim, também assumia caráter orientador da leitura, e era reiterado numa das frases mais famosas do artigo, em que se valorizava o passado e a história locais e, sem descartar os possíveis diálogos com o conjunto da história Ocidental, afirmava-se uma tradição particular:

A história da América, dos incas para cá, deve ser ensinada minuciosamente, mesmo que não se ensine a dos arcontes da Grécia. A nossa Grécia é preferível à Grécia que não é nossa (MARTí, 1983, p. 197).

"Nossa América": sem os adjetivos "Hispânica", "Ibérica” ou mesmo "Latina” - expressão que já existia, embora fosse raramente empregada, e nunca no sentido que hoje lhe atribuímos -, que acabavam por associá-la ao antigo colonizador (ou, no caso de Cuba, ao colonizador ainda presente), e com o pronome possessivo, que indicava procedência, 
conquista da própria terra e pertença à comunidade que nela vivia. "Nossa América”, em suma, era indicativo da especificidade da fração da América que não coincidia com os Estados Unidos, logo, não podia pertencer a eles; era uma ideia resistente - ele já afirmara que "as trincheiras de ideias valem mais do que as trincheiras de pedras” (MARTÍ, 1983, p. 194) - e, por meio dela, Martí pretendia encontrar o lugar de Cuba num continente de Estados nacionais autônomos e, mais, o espelho plural que denotasse passado, presente e futuro americanos.

\section{III}

Muito distante dos embates militares enfrentados por Martí, Joaquim de Souza Andrade acabou por desembocar em percepções algo semelhantes acerca da América e dos americanos e as representou no Guesa errante (depois rebatizado como O Guesa), que, para Haroldo de Campos, foi um dos dois únicos poemas "transamericanos" já feitos (CAMPOS; CAMPOS, 2002, p. 548). ${ }^{4}$

Composto numa estrutura bastante rigorosa e homogênea - treze cantos, quase integralmente escritos em quartetos decassílabos, com rimas cruzadas ou enlaçadas -, o Guesa errante começou a ser preparado durante a longa viagem que o maranhense realizou, de 1858 a 186o, pela bacia do rio Amazonas. Ele vinha de uma temporada de estudos de engenharia e grego, na França, e de rápida passagem pela Faculdade de Medicina do Rio de Janeiro. Essa viagem foi o primeiro contato efetivo de Sousândrade com as populações nativas da região que, nesse momento, já expunham evidentes marcas de degradação em sua organização social, legadas pelo longo período colonial e intocadas pelo insuficiente Império. A construção do poema, com a publicação ocasional de partes dele, acompanhou o poeta nos deslocamentos que, nos anos 1860, o levaram de volta ao Maranhão e, depois, a Nova York, onde se instalou em 1871 e viveu por catorze anos. O retorno ao Brasil, em 1885, deu-se numa longa viagem, que incluiu passagens por Peru e Chile, intensificando o contato de Sousândrade com os países hispano-americanos e, simultaneamente, com a experiência republicana. A (re)escritura do poema épico ganhou,

${ }_{4}^{4}$ O outro, segundo Haroldo de Campos, seria o Canto geral, de Pablo Neruda, escrito entre 1937 e 1950 . 
então, outra dimensão e prosseguiu até o final da vida do autor: no princípio de 1902, um mês antes de morrer, ele ainda publicou uma continuação d'O Guesa em O Federalista, jornal para o qual contribuía havia quase dez anos. ${ }^{5}$

Elejamaisabandonou, tampouco, a defesa dos princípios republicanos e a reflexão sobre os caminhos que as repúblicas americanas percorriam e essa é a primeira correlação óbvia entre sua obra e os escritos martianos. A segunda relação entre os dois autores é igualmente fácil de notar: as longas temporadas vividas em Nova York e a simultaneidade da estadia de ambos lá por pelo menos quatro anos (da instalação de Martí na cidade, em 1881, até o retorno de Sousândrade ao Brasil, em 1885). De qualquer forma, apesar de não existirem menções diretas a Martí na obra de Sousândrade (nem, evidentemente, vice-versa), é bem provável que o maranhense tivesse tomado conhecimento das ideias e dos escritos do cubano: seu interesse pelas lutas de independência e pelos processos de formação e consolidação nacional na América Hispânica, Cuba incluída, certamente o permitiria (CUCCAGNA, 2004, p. 186). Um terceiro e inquestionável paralelo entre ambos está na coincidência de leituras: ambos leram e citaram efusivamente Bolívar e San Martín. ${ }^{6}$

Nenhuma dessas sincronias - todas importantes -, porém, foi mais significativa do que o declarado anti-norte-americanismo que percorreu as duas obras - na poesia e no ensaio - e o esforço de invenção de uma imagem da América unida. ${ }^{7}$ Não casualmente, a proposição inicial dessas questões n'O Guesa representa, como observaram Augusto e Haroldo de Campos, os únicos momentos em que a estrutura regular da obra é rompida: no Canto II (“Tatuturema”, referente às viagens pelo Amazonas no final da década de 1850) e no Canto X ("Inferno em Wall Street", de 1873-84 ou 1888), as estrofes são de cinco versos, a métrica é desigual e variante (2 a 6 sílabas no Canto I; 8 no Canto X), o esquema de rimas é

\footnotetext{
${ }_{5}^{5}$ Os passos da elaboração do poema são mais detalhadamente descritos em LOBO, 2005, e sobretudo em CAMPOS; CAMPOS, 2002.

${ }^{6}$ As leituras coincidentes não se limitaram ao panorama hispano-americano; elas incluíam o repertório de formação liberal por que ambos passaram, contando com autores franceses do século XVIII, especialmente Rousseau, e com os pensadores da independência norte-americana. A mesma proximidade ocorre na leitura de poesia, com o repetido apreço de ambos por Emerson e Walt Whitman (CUCCAGNA, 2004, p. 186).

${ }^{7}$ Silvio Romero notou, a propósito, que Sousândrade, "de nossos poetas é, creio, o único a ocupar-se de assunto colhido nas repúblicas espanholas" (ROMERO, 1888, p. 1161-1165, apud CAMPOS; CAMPOS, 2002, p. 50).
} 
abccb, o quarto verso faz rima interna e provoca "efeitos de deformação expressiva, muitas vezes burlesca", uma "farsa poética" (CAMPOS; CAMPOS, 2002, p. 51; 55). A similaridade atravessou os quinze ou vinte anos que separaram a escritura da publicação de cada um dos cantos e revelou a preocupação de demarcar os dois momentos de tensão mais acentuada do poema com a "desorganização" estrutural; para os irmãos Campos, trata-se de assegurar a percepção do caráter "infernal”, "fáustico", tanto da condição dos indígenas que viviam, em condições de miséria, às margens dos rio Negro, Solimões e Amazonas, quanto da efervescência do mercado financeiro nova-iorquino.

“Tatuturema” representava a instauração do tema do indígena e da necessidade de redimensionar seu papel no passado e no futuro americanos; "Inferno em Wall Street" trazia denúncia de outra ordem, relativa ao prevalecimento do capital financeiro e à desumanização manifesta nos enredos cotidianos dos Estados Unidos. "Inferno em Wall Street" mostrava, ainda, Nova York como um microcosmo, para onde confluíam todos os problemas e impasses nacionais e internacionais; lugar onde aportavam as notícias repentinas de eventos ocorridos do outro lado do Atlântico (por exemplo, a Comuna de Paris, greves de ferroviários ou a exploração da borracha); cenário em que ecoavam vozes de políticos e de investidores repetitivos e ávidos na obsessão pelo dinheiro e pelo lucro, imersos em diálogos confusos, enfatizados, no poema, pela proliferação de sinais gráficos e de frases que beiram o ridículo e o insano:

“- Harlem! Erie! Central! Pennsylvania!

= Milhão! cem milhões!! mil milhões!!!

- Young é Grant! Jackson,

Atkinson!

Vanderbilts, Jay Goulds, anões!"

“- Dois! três! cinco mil! se jogardes

Senhor, tereis cinco milhões!

= Ganhou! ha! haa! haaa!

Hurrah! ah!..

- Sumiram ... seriam ladrões?..”

"Strike! do Atlântico ao Pacífico!

= Aos Bancos! Ao Erário-tutor!

- Strike, Arthur! Canalha,

Esbandalha!

Queima, assalta! (Reino de horror!)”

(apud CAMPOS; CAMPOS, 2002, p. 343-344; 352) 
Num mundo - "(Reino de horror!)" - em que o dinheiro contaminava todas as relações, a cidade-síntese Nova York reunia nomes de empresários, financistas e políticos. Em contraste com a dignificação que recebiam no mundo das finanças - e segundo a lógica desse mundo -, tais personagens apareciam, no poema, em pleno e ganancioso êxtase, para serem rapidamente confrontados pelo irônico e reativo arremate de uma das estrofes: “- Sumiram ... Seriam ladrões?".

A estética da reação desenvolvida pelo texto ampliava-se e se consumava num contraponto ainda maior, e menos circunstancial: a presença positivada do Guesa, verdadeiro antônimo do frenesi capitalista norte-americano. ${ }^{8} \mathrm{O}$ poeta-narrador assumia a persona do Guesa e viajava errática e ininterruptamente pela América; alternava experiências idílicas e eventos trágicos, recuperava o passado pré-colombiano, diagnosticava a persistência dos males trazidos pelos conquistadores europeus, criticava acidamente a elite econômica e política que, na colônia ou na república, assumiu o controle dos Estados e colaborou na obra de deformação-degeneração continental. Tais repúblicas, afinal, eram imperfeitas, atestava o sempre-republicano Sousândrade, pelo menos na forma como elas se constituíram na América, com sua precária modernidade, com a exclusão de parte majoritária e decisiva da sociedade, com o desprezo arrogante pelo passado indígena; e pela forma como a America modelou sua originalmente valiosa república, tornando-a sinal de perigo, inferno, destruição. Claro que a árida constatação não levou o autor a abandonar seus princípios republicanos; ao contrário, O Guesa é seu maior exercício de reflexão política - bem mais, inclusive, do que seus ensaios sobre o assunto - acerca da necessidade e dos caminhos possíveis para a refundação das repúblicas americanas - as "repúblicas dolorosas da América”, nas palavras de Martí.

O Guesa, indígena redentor recuperado por Sousândrade, é inovador: dialoga com o indianismo romântico brasileiro, mas não se resume a ele -

\footnotetext{
${ }^{8}$ Personagem lendária, oriunda do culto solar de indígenas da Colômbia. O nome "guesa” significa "errante", "sem lar" (daí o nome inicial do livro - Guesa Errante - ser, na verdade, um pleonasmo). Era uma criança roubada dos pais e destinada a ser oferecida em sacrifício a Bochica, herói civilizador da tradição muísca. Aos quinze anos de idade, realizava-se o ritual, que se encerrava quando o coração da vítima era arrancado e oferecido simbolicamente ao Sol, com a finalidade de assegurar a união cósmica que mantinha associados, ainda que precariamente, homens e divindade e que, a cada novo Guesa, era confirmado e renovado. Provavelmente Sousândrade teve contato com a lenda e seu significado unificador por meio da leitura de Ferdinand Denis e, sobretudo, de Humboldt (CUCCAGNA, 2004; LOBO, 2005).
} 
o que seria, de resto, contraditório em relação a seu esforço americanista -, nem perde de vista a precariedade da condição social das populações indígenas na América do século XIX. Ou seja, a idealização romântica do bom selvagem - quase sempre estático, passado que se reproduz no presente - mantém-se em contínua tensão com o gesto político e humanitário que permitia a Sousândrade associar a figura idealizada, de origem mítica, ao indígena real, presente e miserável, das margens do rio Amazonas ou de tantas partes da América Hispânica. ${ }^{9}$

Só simbolicamentea viagem do Guesa pode ser equiparadaà do próprio Sousândrade; seus percursos divergem; o ser mítico move-se de forma errática e cobre todo o continente em seu périplo de reconhecimento da história e de proposição de um futuro utópico, em que a ideia de república de fato se afirmasse e as tantas repúblicas se unissem. O modelo de união e de ordenamento social assumido por O Guesa veio do Império Inca - o mesmo império que, para Martí, indicava o ponto de partida da história da América a ser ensinada nas escolas. ${ }^{10}$ Os incas fundadores, tratados no Canto XI, representavam os heróis da Panamérica, cujo coração residia no centro geográfico do continente e pátria do Guesa, a Colômbia:

9 Sobre a idealização do indígena em Sousândrade, veja-se CUCCAGNA, 2004. A transcendência de $O$ Guesa, ressalta Jorge Schwartz, deve ser compreendida em mais de um sentido: Sousândrade extrapolou os limites do Romantismo literário brasileiro e ultrapassou as fronteiras do Brasil e da América Latina (além da questão norte-americana, há, no Canto VII, menções à Europa e à África), tornando-se "internacionalista" e assumindo um cosmopolitismo que o aproximou de Charles Baudelaire e de Walt Whitman: "Assim como os Chants de Maldoror (1969) de Lautréamont, o Guesa Errante deve ser considerado como um parêntese literário, se o analisarmos em sua perspectiva diacrônica. Sousândrade, cronologicamente inserido no romantismo brasileiro, apresenta uma escritura de caráter excepcional que vai romper com os modelos tradicionais de sua época” (SCHWARTZ, 1983, p. 8). Luiz Costa Lima explora com agudeza o movimento de contenção e ultrapassagem de Sousândrade em relação ao Romantismo (In: CAMPOS; CAMPOS, 2002, p. 461-503; especialmente p. 495-496). Entre os muitos vazios nos estudos sobre Sousândrade, persiste inexplorado outro diálogo hispano-americano possível: o de sua obra com a do peruano Manuel González Prada (1844-1918). Também nesse caso, não houve contato direto, mas é bastante interessante notar semelhanças no empenho contemporâneo de ambos para a renovação da visão da condição dos nativos, abandonando as percepções apenas pedagógicas ou culturais e concebendo a questão indígena como política e social.

${ }^{10}$ Haroldo de Campos lembra que Sousândrade desenvolve, no que concerne ao campo hispano-americano, outro tipo de idealização: a do Império Inca. Manifesta desde o século XVII - com Garcilaso de la Vega - e persistente ainda no século XX, tal visão caracterizava a sociedade inca como coletivista e "republicana" (In: CAMPOS; CAMPOS, 2002, p. 545-558). 
Traçada outra vereis, linha equatória Unindo os mares, dividindo as terras A dois imensos povos e a uma glória De confederações, a Sul, das serras

Ândeas e os áureos vales do Amazonas, Representa-a Bolívar; tendo a Norte Industriosa, Washington; e as zonas Daqui a cada polo, irmãs e fortes.

Nem é debalde que o planeta gira, Dando formas aos novos continentes. Um amplo coração o austral, que sente; E o boreal, pulmões, o que respira.

E esta é a pátria central viçosa amante, Que a tanta glória nos convida e anima, Colômbia do equador! raça latina, Tão sonhadora qual o Guesa Errante!

A errância do Guesa lhe era essencial. Ele não cansava de circular, era um viajante no tempo e no espaço, um cronista interno da América, que revelava e expunha aos demais o que em geral lhes passava despercebido; era um poeta-peregrino, que fundava uma percepção da América em movimento, "transamericana", utopia que se cumpriria no futuro. A denúncia dos Estados Unidos como um império da ambição tampouco implicava a exclusão do país da ampla reunião a ser inventada na América. Da mesma forma, o Brasil, normalmente ignorado no pensamento americanista procedente da América Hispânica, comparecia ao banquete móvel celebrado pelo Guesa em sua errância prazerosa, na disposição de ver, até nas comunidades degradadas das margens do Amazonas, o germe triunfante de uma América unida:

E é do Guesa a existência do futuro;

Viver nas terras do porvir, ao Guesa

Compraz, se alimentar de pão venturo,

Crenças do Além, no amor da Natureza:

Fecundas terras, onde lhe chovia

Eterno pensamento, irradioso,

Cristalino, a que ao Sol ideal o dia

Ortivo incásio abriu, doce e formoso!

(apud CAMPOS; CAMPOS, 2002, p. 258) 
Na tensão e da precariedade, nasceria a América unida; Estados Unidos como inferno e contínua ameaça interna; Brasil e América Hispânica associados; América como utopia futura, que reconheceria seu passado, miticamente expresso; Panamérica; Transamérica: a América de Sousândrade também era "nossa".

\section{IV}

Martí e Sousândrade nunca se conheceram pessoalmente. O brasileiro acompanhou as lutas de independência em Cuba e as citou em duas passagens d'O Guesa (Canto IX e Canto XII); é improvável que Martí tenha sabido algo de Sousândrade. Evidentemente as estadias simultâneas em Nova York contribuíram para a percepção aguda e crítica do império financeiro que se construía nos Estados Unidos e que parecia tão assimétrico em relação à vida das sociedades ao Sul do Rio Grande.

Sousândrade e Martí notaram com facilidade os novos caminhos que a história norte-americana seguia. Ambos, afinal, haviam acompanhado, de perto ou de longe, a Guerra Civil norte-americana - Martí não citara por acaso o discurso de Lincoln sobre a "casa dividida" - e o consequente predomínio industrialista ianque, que levava muitos norte-americanos a elegerem o Sul como o novo objeto do desejo, numa reorientação do mítico Destino Manifesto que antes sustentara o imaginário do avanço para o Oeste e que agora buscava outros limites a serem rompidos (PRATT, 1992).

Depois da Guerra Civil, os movimentos expansionistas norte-americanos - que nunca tinham se desenvolvido de forma equânime sobre o conjunto do continente e até então se voltavam essencialmente para as áreas vizinhas do Caribe, México ou América Central - ganharam evidência e consistência: havia fronteiras a serem ultrapassadas, o capital financeiro atravessava um processo de transnacionalização, a obtenção de mais e maiores mercados ampliava a potencialidade econômica e gerava nichos protegidos de atuação. O próprio discurso que acompanhou o intervencionismo estadunidense variou nas formas e manifestações, mas um de seus marcos principais foi justamente o conjunto de proposições norte-americanas no citado Congresso Panamericano de 1889. Martí, observador sensível e analista agudo, com a experiência de quem vinha de Cuba - que desde o século XVI estivera sob os olhos atentos dos Estados Unidos -, reconheceu, ali, uma ameaça à autonomia política 
recém-conquistada da América Hispânica (ou, no caso cubano, ainda não conquistada).

É verdade que Martí e Sousândrade não foram os únicos a perceber o risco representado pela aproximação sistemática com os Estados Unidos. O brasileiro Eduardo Prado ou o uruguaio José Enrique Rodó exemplificaram outras reações e intenções de afastamento em relação ao vizinho nortista. Prado pretendeu justificar a especificidade nacional (inclusive como estratégia de defesa da monarquia e crítica ao ideal republicano) e acabou por dar as costas ao continente inteiro. Rodó enxergou uma América latinizada e contribuiu decisivamente para a validação interna do referente "América Latina". Ambos, porém, preferiram situar sua Lua e seu Sol na Europa, não no passado ou no presente locais. ${ }^{11}$ Sousândrade e Martí seguiram outras estrelas - reais ou imaginárias -, professaram mitologia distinta daquela do dinheiro e da riqueza, voltaram seus olhos para o interior da América e para o passado do continente e aí acreditaram encontrar origens e possibilidades, novos sentidos para os povos americanos. Tentaram desbravar uma América alternativa. Na contramão do modelo estadunidense da America triunfante, inventaram outra América: assim nasceram a "Nossa América" e a "Transamérica”, por onde errava o Guesa, onde o Grande Semi lançava as sementes do futuro.

Inevitável, também, atestar a peculiaridade do "transamericanismo" de Sousândrade, não apenas mais extenso espacialmente que o de Martí, mas saído das letras de um brasileiro e com antecipação de pelo menos trinta anos em relação à "Nossa América". O Brasil, afinal, não apenas olhava pouco para a vizinhança e era pouco (ou negativamente) notado por ela; o tema da ameaça norte-americana era menos notável aqui do que pelas lentes inevitavelmente temperadas de um cubano imerso na luta de independência e nas infinitas contendas com os "anexionistas". Infelizmente, a precocidade e a singularidade do olhar e do projeto "transamericano" de Sousândrade não impediram que sua difusão e eficácia tenham sido mínimas, quase nulas - ou talvez tenha sido exatamente essa precocidade e essa singularidade, tão estranhas ao debate da época, que limitaram o número de leitores do épico. Dois contemporâneos do maranhense previram que $O$ Guesa só seria lido "50 anos depois" (CAMPOS; CAMPOS, 2002, p. 24). Pior: a previsão estava

${ }^{11}$ Eduardo Prado publicou A ilusão americana em 1893; José Enrique Rodó lançou a primeira edição de Ariel em 1900. 
errada. Demorou mais de sessenta anos depois de sua morte, em 1902, para que a obra fosse relembrada. Após décadas de esquecimento, a $R e$ visão de Sousândrade, livro que o recuperou, só saiu em 1964. Martí, ao contrário, foi sistematicamente incorporado nas invenções de América produzidas no século XX e a "Nossa América" é considerada precursora da noção presente de América Latina, da disposição de reconhecer a peculiaridade dessa outra América e em/de suas diversas expressões.

Sousândrade e Martí fundavam, assim, a "América que não é America", uma América cuja adjetivação não se refira ao antigo colonizador, como ocorre, por exemplo, em "América Ibérica” ou "América Latina”. Mesmo que ambos tenham partido de um reconhecimento pela negação, pela recusa inicial dos Estados Unidos, não se limitaram a ela para pensar seus horizontes possíveis - horizontes desvelados numa longa e tortuosa viagem ou pela ingestão do improvável vinho de banana.

\section{REFERÊNCIAS BIBLIOGRÁFICAS}

CAMPOS, Haroldo de. A peregrinação transamericana do Guesa de Sousândrade. In: CAMPOS, Augusto de; CAMPOS, Haroldo de. Re visão de Sousândrade. 3. ed. rev. e ampl. São Paulo: Perspectiva, 2002.

CAMPOS, Augusto de; CAMPOS, Haroldo de. Re visão de Sousândrade. 3. ed. rev. e ampl. São Paulo: Perspectiva, 2002.

CARVALHO, Eugenio Rezende. Nossa América: a utopia de um novo mundo. São Paulo: Anita Garibaldi, 2001.

CHIAMPI, lrlemar. O realismo maravilhoso. São Paulo: Perspectiva, 1980.

CUCCAGNA, Claudio. A visão do ameríndio na obra de Sousândrade. Tradução de Wilma Katinsky Barreto de Souza. São Paulo: Hucitec, 2004.

LIMA, Luiz Costa. O campo visual de uma experiência antecipadora. In: CAMPOS, Augusto de; CAMPOS, Haroldo de. Re visão de Sousândrade. 3. ed. rev. e ampl. São Paulo: Perspectiva, 2002.

GOTT, Richard. Cuba: uma nova história. Tradução de Renato Aguiar. Rio de Janeiro: Jorge Zahar, 2006.

LOBO, Luiza. Épica e modernidade em Sousândrade. Rio de Janeiro: 7 Letras, 2005.

MARTÍ, José. Nossa América. São Paulo: Hucitec, 1983.

PRADO, Eduardo. A ilusão americana. São Paulo: Ibrasa, 1980. 
PRADO, Maria Ligia Coelho. América Latina no século XIX: tramas, textos e telas. São Paulo: Edusp; Florianópolis: Edusc, 1999.

PRATT, Mary Louise. Imperial Eyes: Travel Writing and Transculturation. Nova York: Routledge, 1992.

RAMOS, Julio. Desencuentros de la modernidad en América Latina: literatura y política en el siglo XIX. México: Fondo de Cultura Económica, 1989.

REINATO, Pedro Martins. “A própria forma do bárbaro domínio”: elementos da composição poética em $O$ Guesa, de Sousândrade. Dissertação de Mestrado. Programa de Pós-Graduação em Literatura Brasileira. Departamento de Letras Clássicas e Vernáculas, Faculdade de Filosofia, Letras e Ciências Humanas, Universidade de São Paulo, São Paulo, 2008.

RODÓ, José Enríque. Ariel. Tradução de Denise Bottmann. Campinas: Editora da Unicamp, 1991.

ROJAS, Rafael. La vanguardia peregrina: el escritor cubano, la tradición y el exilio. México: Fondo de Cultura Económica, 2013.

SCHWARTZ, Jorge. Vanguarda e cosmopolitismo na década de 20: Oliverio Girondo e Oswald de Andrade. São Paulo: Perspectiva, 1983.

SOUSÂNDRADE [Joaquim de Souza Andrade]. Poesia e prosa reunidas de Sousândrade (org.: Frederick Williams). São Luís: Edições AML, 2003.

VILLAÇA, Mariana Martins. José Martí. São Paulo: Memorial da América Latina, 2008.

WILLIAMS, Frederick. Sousândrade: vida e obra. São Luís: Sioge, 1976. 